\title{
INVESTIGATION OF TECHNOLOGICAL TRENDS IN SHADING DEVICES THROUGH PATENT ANALYSIS
}

\author{
Yeng-Horng PERNG, Yu-Ying HUANG \\ Department of Architecture, National Taiwan University of Science and Technology, \\ \#43, Sec. 4, Keelung Rd., 106 Taipei, Taiwan
}

Received 17 Apr 2013; accepted 17 Oct 2013

\begin{abstract}
In recent years, the issues of energy use reduction and sustainable development have garnered considerable interest. This study has conducted a patent search using United States Patent and Trademarks Office (USPTO) data to investigate technological trends in sustainable development, using shading devices for buildings as an example, because they have the potential to save energy by effectively preventing heat from coming indoors, and lowering the indoor heat load. The purpose of this study was to explore the status of shading devices and analyze patent activity, major assignees, assignee countries, core technology fields, patent citations, potential competitors of patent assignees, and developmental path based on patent analysis using a database that spanned the years from 1974 to 2011. The results provide a clear picture of, and evidence for, the pattern of shading device technology; they suggest that automatic sensing shading devices are the focus of current technological developments, thus saving time and costs in future research development.
\end{abstract}

Keywords: architecture, patent analysis, shading device, social network analysis.

\section{Introduction}

In a knowledge economy, intellectual property rights are a significant asset for creating value (Hanel 2006). Patents are a concrete symbol of technological innovation and development and involve substantial core technologies that are specific indicators for evaluating the developmental ability of individuals, companies, enterprises, and countries (Griliches 1990; McAleer, Slottje 2005). A patent specification is a public document that contains data on the application date, issue date, priority date, assignee, inventor, assignee country, inventor country, International Patent Classification (IPC), and reference citations. Patent content, which is readily available via searchable patent gazettes (La Rocca, Tooren 2012; Ma, Lee 2008; Spear 1996), provides valuable information regarding any number of relevant technologies. Transforming patent data into patent information for application contributes to knowledge diffusion, promotes technological development, and innovation (Chen, Y.-S., Chen, B.-Y. 2011; Co 2002; Globerman et al. 2000; Karki 1997). The concrete result of publicly accessible patent information is improved technological innovation and development; therefore the importance of the patent cannot be ignored.

Patent analysis consists of reading and selecting relevant extracted patent data from a patent search, determining whether the patent is related to the research subject, deciding on the appropriate content and size of the patent analysis sample, and conducting a statistical analysis via a systematic method. Relevant patent information is deduced after the discovered patent data are read and organized. Quantitative statistical analysis is then conducted and a correlational patent map is drawn based on the statistical analysis. Meanwhile, relevant information is explained and analyzed, thus contributing patent intelligence to help grasp the trend of technological development in a specific field.

Several studies have applied patent data to explore various patenting activities in different fields. Daim and Intarode (2009) applied patent analysis to evaluate the technologies of building material for manufacture in Thailand. Trappey et al. (2011) applied patent analysis to explore trends in the development of radio frequency identification (RFID) technology and to evaluate possible market opportunities from the State Intellectual Property Office of the People's Republic of China (SIPO) database during the period 1995 to 2008. Chen, Y.-S. and Chen, B.-Y. (2011) applied patent analysis to explore the cooperative competition relationship between the two light emitting diode (LED) manufactures, Nichia and Osram, and found that their strategic interaction changed from full competition to co-operation to create a

Corresponding author: Yu-Ying Huang

E-mail:d9813002@mail.ntust.edu.tw 
win-win model for both companies over time. Yoon and Kim (2011) proposed a patent network method based on semantic analysis using patents related to synthesis of carbon nanotubes, which can be useful in identifying technological trends in rapidly evolving industries. Yoon et al. (2011) proposed the invention property-function network analysis (IPFN) method to extract properties and functions from patents related to silicon-based thin film solar cells, and to identify the technological implications of properties and functions using social network analysis (SNA), which can assist experts in identifying the innovation trends of new or emerging technologies.

Other studies have applied patent citation information to investigate the development of patented technologies in different fields. Patel and Ward (2011) used patent citation patterns to estimate competition in innovation markets and found that a firm's market value increases when its patent portfolio is cited. Cheng (2012) used patent citation data to investigate and explore the diffusion of advanced ceramic powders technology. Wu and Mathews (2012) used patent citation data to investigate the respective knowledge flows of the solar photovoltaic industry in Taiwan, Korea, and China from the USPTO database during the period 1984 to 2008 , thereby indicating a shift from imitation to innovation.

As climate change and global warming gradually worsen and global temperatures increase each year, air conditioning and lighting continue to account for the greatest proportion of buildings' daily energy consumption. Shading devices for buildings are a critical technology used in the design of green buildings to help reduce energy consumption and air conditioning load while improving light management. The shading devices' core functions include shading, light direction, rain obstruction, and ventilation. Shading devices can be divided into external and internal shading classes, according to their location, both of which successfully prevent heat from entering indoors, reduce the indoor temperature elevation and decrease the indoor air conditioning load, thus helping to achieve a broader objective of reduced energy consumption. When mounting a shading device, environmental factors such as the location of the building and the angle of incoming sunlight should be considered to achieve optimal shading effects. Both internal and external shading devices save energy by effectively preventing heat from coming indoors, and lowering the indoor heat load; thus, energy consumption caused by air conditioning is reduced, which, in turn, reduces waste, cuts operational costs, and delivers positive impacts on both health and the environment (Cho et al. 1995; Datta 2001; Florides et al. 2000; Palmero-Marrero, Oliveira 2010; Yener 1998). However, patent data analysis has never been applied to explore patenting activities and technology development with respect to shading devices. Consequently, this study selected the technological development of "shading devices for buildings" to explore through the analysis of patenting activities. The purpose of this study is to explore the current status of patent activity, major assignees, assignee countries, and core technology fields, using 1974-2011 USPTO data to discover the potential competitors of patent assignees and the main patent path, and to monitor the technical relevance of competitors and technological development in the technology field.

The research framework of the paper is structured as follows. In Section 1, we introduce the research background, motivation, method and purpose of the paper. Section 2 describes the methodology and procedures for the collection of data in the USPTO database. In Section 3, we apply methods to explore the status of patent activity, major assignees, assignee countries, core technology fields, potential competitors, and developmental path in the technology field during the period 1974 to 2011. In the last section, we provide the primary conclusions of this study. We are confident that the results of this study can provide a basis for better understanding patenting activities and technological development related to shading devices, saving time and cost for future research development.

\section{Materials and methods}

\subsection{Materials}

The patent data in this study of sun shading plates were obtained from the USPTO database entries from 1974 to 2011. Patent retrieval queries were composed of keywords and IPC classifications. The search proceeded as follows: (1) Searching with keywords, which retrieved information from titles, abstracts, and claims, combined with IPC classifications, as shown in Table 1; (2) Reviewing related bibliographic information and drawings in the collection of patents; (3) Filtering out irrelevant patents that contain the keywords "vehicle", "automobile", "car", "motorcycle", "storm", or "hurricane" in the title, abstract, or claims; (4) Generating a patent set related to shading devices. In this study, the patent search retrieved a total of 742 patents dated 1974-2011 from

Table 1. Patent retrieval query from the USPTO granted patent database

\begin{tabular}{ll}
\hline Patent retrieval query & Patents \\
\hline ((TTL/(shad\$ or shutter\$) or & 742 (after eliminating \\
ABST/(shad\$ or shutter\$) & irrelevant patents) \\
or ACLM/(shad\$ or & \\
shutter\$)) andnot (TTL/ \\
(vehicle or automobile or \\
car or motorcycle or storm \\
or hurricane) or ABST/ \\
(vehicle or automobile or \\
car or motorcycle or storm \\
or hurricane) or ACLM/ \\
(vehicle or automobile or car \\
or motorcycle or storm or \\
hurricane)) and ICL/(E06B\$ \\
or A47H\$) and ISD/1/1/1974- \\
$>12 / 31 / 2011$
\end{tabular}


the USPTO granted patent database. The resulting bibliographic information was then extracted from the patent document and converted into Pajek format to analyze and construct a graph visualization of the network.

\subsection{Methods}

This section focuses on the research frame of patent analysis as shown in Figure 1, including patent analysis, and SNA.

\subsubsection{Patent analysis}

The specification of a patent is a public document that is issued by a patent authority after examining the application file of the applicant for a patent (List 2010; Sorenson et al. 2006). The World Intellectual Property Organization (WIPO) has adopted internationally agreed upon numbers for the identification of data (INID) code to distinguish bibliographic data in a patent document, which facilitates universal communication (i.e. compatibility with every language and written word) by using a twodigit number to represent each piece of data. Presented in a decimal system, numbers such as 10, 20, and 30, indicate the main categories for detailed classifications. The concept is similar to corresponding numbers, and provided the individual knows what subject each code represents, the individual can easily recognize its content. Accordingly, the patent document describes the bibliographic data and core technology, as shown in Figure 2. The information in the patent is open and the relevant bibliographic data of the patent document can be obtained through a patent search.

Patent analysis primarily refers to searches for thematically relevant technologies and consists of conducting a systematic statistical analysis of the selected patent data using a bibliometric method and portraying a patent map (Karki 1997). A patent analysis allows the viewer to recognize and understand developmental trends and the current status of technology, to grasp the core technology, to identify the technologies used by the competition, to assess their own developmental potential, and to plan their developmental path. A patent analysis consists of two types of analysis, quantitative and qualitative, according to the content of the patent data. A quantitative analysis requires summarizing the external characteristics of patent literature by following certain indicators, such as application date, issue date, publication date, priority date, assignee, inventor, assignee country, inventor country, IPC, and reference citations, and thereafter analyzing and explaining the data. A patent analysis contributes to all of the following: understanding the developmental trends and lifecycles of related technologies, tracing and analyzing the competitions' technologies (Yuan et al. 2010), setting developmental directions, exploring potential technologies, predicting new technologies (Ernst 1997), monitoring competitors' activities (Wilson 1987), and assessing business patent management.

\subsubsection{Social network analysis}

Originating several decades ago in the field of social science, social network theory examines the relationships between individuals, groups, communities, organizations, and company employees by analyzing how those relationships form networks of nodes and links, and examining attributes such as network size and link intensity (Boyd, Ellison 2007; Scott 1988). SNA is a scientific and systematic method in which every role is a node, with links being used to show the relationships between nodes (Scott 1988). Visualized networks may be directed or undirected; in the latter, simple lines are used to designate links between nodes, whereas directional arrows are used in the former. Context and meaning can be derived from data subjected to network analysis through the use of some standard indicators. Freeman (1978) proposed SNA indicators such as density, degree centrality, betweenness centrality and closeness centrality to measure important or prominent nodes in a network, which can be effective in discovering the central nodes of the network. SNA indicators can be defined as follows:

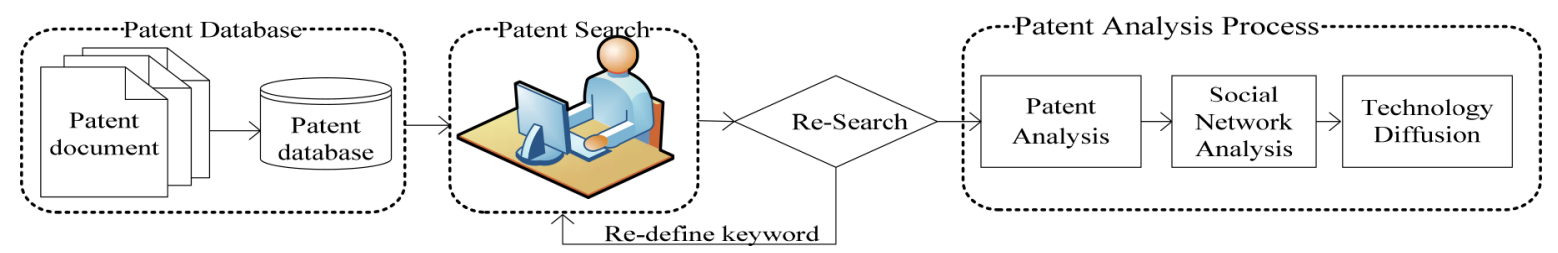

Fig. 1. Research frame of patent analysis

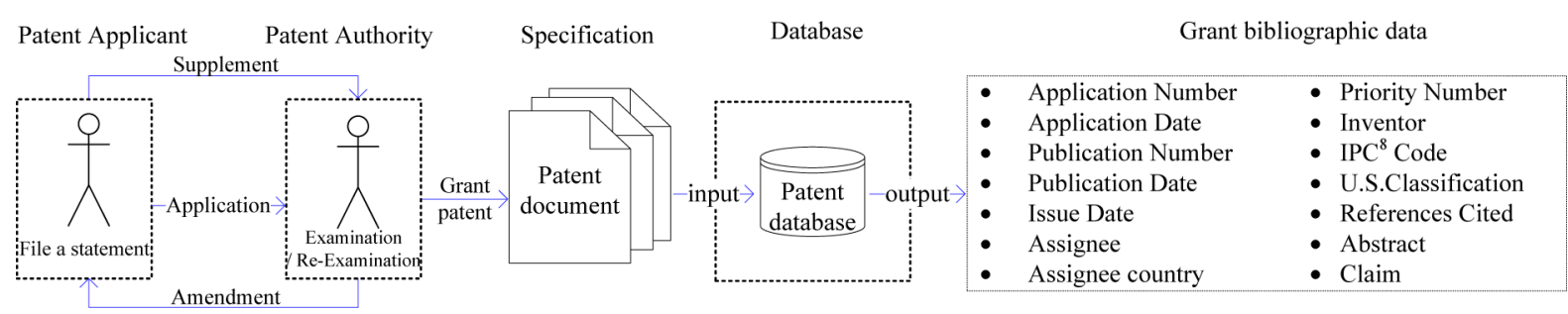

Fig. 2. Patent document 
(1) Density

Density $(D)$ is used to measure the count of the number of links to other nodes in a directed or undirected network, as shown in Eqns (1) and (2), respectively. It can be used to identify the completeness of the network (Yoon et al. 2011). A network with high density is highly connected to other nodes:

$$
\begin{gathered}
D=\frac{l}{N(N-1)} ; \\
D=\frac{l}{N(N-1) / 2},
\end{gathered}
$$

where $l$ is the total number of links and $N$ is the total number of nodes in a network.

(2) Degree centrality

Degree centrality $\left(C_{D}\right)$ is used to measure the number of directed or undirected relationships a node has with other nodes in a network, as shown in Eqn (3). This can be used to calculate a node's number of directly connected neighbours in a network. A node with a higher degree centrality indicates that it has more influence and importance than other nodes in a network.

$$
C_{D}\left(p_{k}\right)=\sum_{i=1}^{n} a\left(p_{i}, p_{k}\right)
$$

where $p_{k}$ is a given node ${ }_{k} ; n$ is the total number of nodes; $a\left(p_{i}, p_{k}\right)=\left[1\right.$ if node $_{i}$ and node ${ }_{k}$ are connected by a line, 0 otherwise].

\section{(3) Betweenness centrality}

Betweenness centrality $\left(C_{B}\right)$ is used to measure how often a node is located on the shortest path between other nodes in a network, as shown in Eqn (4). It means a node acts as a bridge connecting any two other nodes, to transfer information in a network. A node having higher betweenness centrality indicates that it has more interaction than other nodes in terms of passing knowledge and information in a network:

$$
C_{B}\left(p_{k}\right)=\sum_{i<j} \frac{\mathrm{g}_{i j}\left(p_{k}\right)}{\mathrm{g}_{i j}},
$$

where $g_{i j}$ is the number of shortest paths from node ${ }_{i}$ to node $_{j} ; g_{i j}\left(p_{k}\right)$ is the number of shortest paths from node ${ }_{i}$ to node ${ }_{j}$ which passes through node ${ }_{k}$.

(4) Closeness centrality

Closeness centrality $\left(C_{C}\right)$ is used to calculate the distance of a node from others in the network, as shown in Eqn (5). A node showing high closeness centrality indicates that it is connected to other nodes by shorter distances and has closer relationships with other nodes than some other nodes in a network.

$$
C_{c}\left(p_{k}\right)=\left[\sum_{i=1}^{n} d\left(p_{i}, p_{k}\right)\right]^{-1},
$$

where $d\left(p_{i}, p_{k}\right)$ is the number of links in the geodesic (shortest distance) linking node ${ }_{i}$ and node ${ }_{k}$.
Patent citation means referencing previous technologies when claiming a patent, through which the applied aspects of a technology (i.e., technological correlations, technology diffusion, and technological values) can been explored (Michel, Bettels 2001). The reference citations of patent bibliographic information include non-patent literature (NPL) references and patent literature (PL) references. NPL refers to journals, articles, books, and conference reports, while PL includes prior arts and relevant citation cases to which patent examiners refer during a patent examination. Because every patent citation link connects to forward and backward patent citations by linking to other prior arts, the trend of technological changes can be identified. A patent citation network is a directed network with its arrow pointing from the cited patent to the citing application to show the flow of information and knowledge, namely, the trajectory of knowledge communication, knowledge diffusion, and technological improvement (Hu 2008; Schmoch 1993).

Technological innovation and development constitute knowledge creation. After a development result claims a patent, which is permitted and announced, the patent specification revealed to the public is beneficial for technology creation and further results in technology diffusion, contributing to the innovative development of an industry. The citation network of a patent has direction, in that it points from a cited patent to a citing patent. Because the relationship between the cited and the citing patent indicates the developmental context of a technology, individuals can observe technological development through a patent citation network. Patents that are often cited have more linkages, suggesting the representativeness of the technology and the significance to guide innovation toward future technologies (Albert et al. 1991; Carpenter et al. 1981; Ernst 1995). Patents that are cited less have lower linkages, suggesting that the technology has no representativeness and little influence on future technologies (Albert et al. 1991; Chang et al. 2009). The core technology is situated in the center of a network that plays a crucial role, thus promoting technology diffusion.

\section{Analysis of results}

\subsection{Patent activity}

After using relevant keywords and IPC classifications to search patents in the field of shading devices, the total number of granted patents from the USPTO database over the past 38 years was 742 . This study then used bibliometric data to analyze the patenting activity during the period 1974 to 2011, as shown in Figure 3. This process provided the number of granted patents for each year. The first patent was applied for in 1974 and granted in 1976. According to the granted patent trend, this study divided this period into three phases. The first phase spans 1974 to 1982 , during which time the number of granted patents 


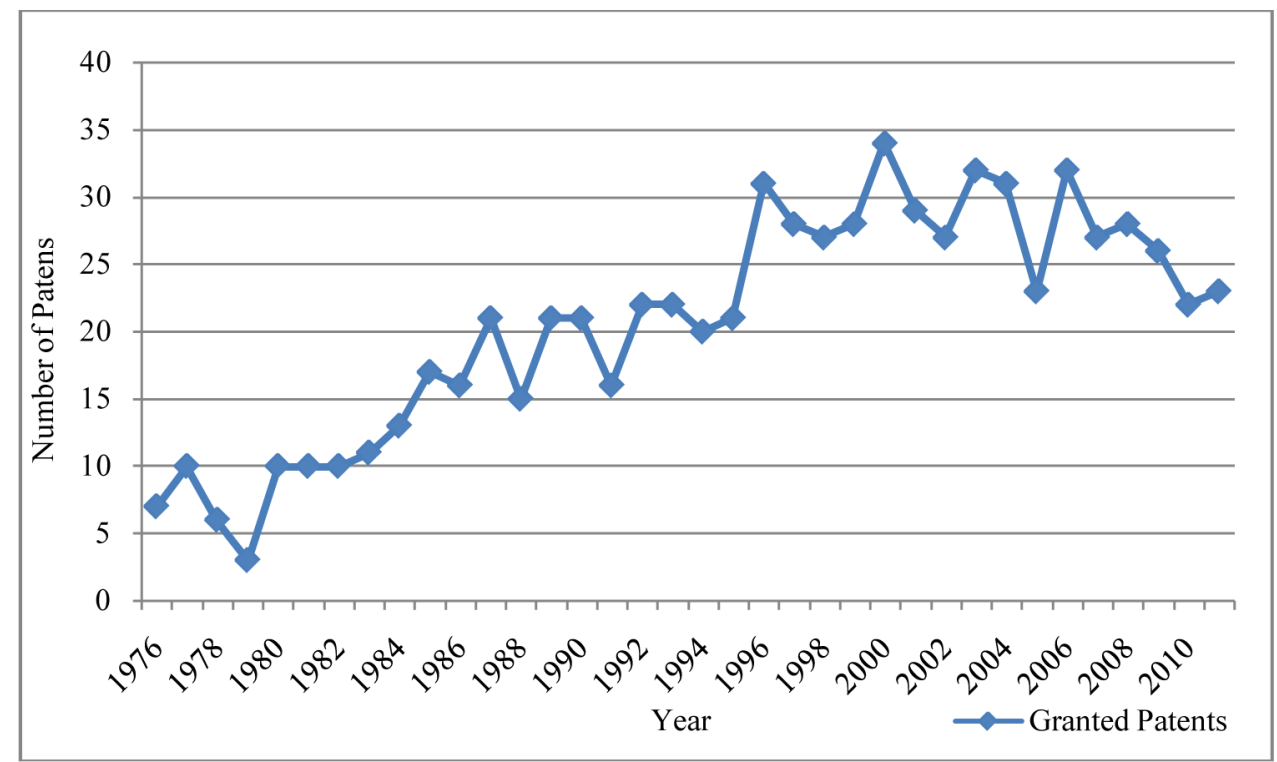

Fig. 3. Number of granted patents during the period 1974-2011

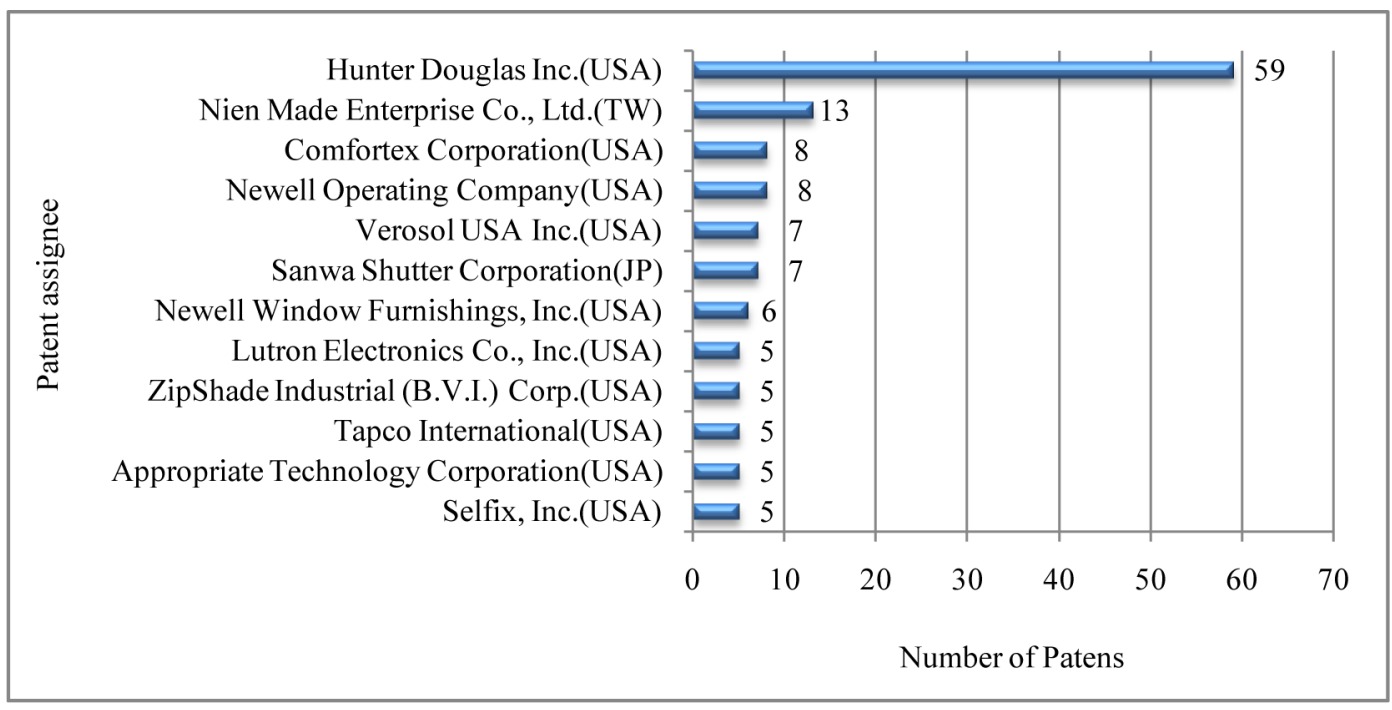

Fig. 4. Top 10 patent assignees in the technology field

increased slowly but was consistently at a rate of less than 10 per year. The second phase spans 1983 to 2000, during which the growth of granted patents increased dramatically after 1984 and continued to increase until 2000. The third phase spans 2001 to 2011, during which the trend of granted patents significantly decreased. This situation suggests that technology in the area of shading devices must become more innovative in the future.

\subsection{Assignee analysis}

The top 10 patent assignees are shown in Figure 4. Figure 4 indicates that companies and corporations have played important roles in patent activity in the area of shading devices. The figure clearly showed that Hunter Douglas Inc. was the leading assignee, having been granted 59 patents in this field, which accounts for $7.95 \%$ of the total number of patents. Nien Made Enterprise Co., Ltd, the only Taiwanese company, was ranked second with 13 granted patents, which accounted for $1.75 \%$ of the total number of granted patents in the field. Comfortex Corporation and Newell Operating Company followed in third place with 8 patents and $1.08 \%$ of the total granted patents in this field. According to Figure 4, this study found that the leading home country of patent assignees in the area of shading devices was the USA, followed by Taiwan and Japan.

\subsection{Assignee analysis by country}

The patent applications used for the study represent 96 countries. As shown in Table 2, this study summarized 
the number and the percentage of patents by the top 10 countries. This table clearly shows that the USA was the leading country with 464 patents, which accounted for $62.53 \%$ of the total number of granted patents in the field. Behind the US, Taiwan ranked second with 78 patents, which accounted for $10.51 \%$ of the granted patents, and Canada ranked third with $35(4.72 \%)$ granted patents in the field. The top 10 countries were granted over $90 \%$ of all patents.

\subsection{IPC analysis of core technology}

As determined by IPC analysis, Table 3 presents the top 5 technology fields for the area of shading devices from 1974 to 2011. As each patent contained one or more IPC codes, the total count of IPCs was greater than the granted patent counts. From the result of analysis in this study, most of granted patents focused on E06B009 with 1,691 , which accounted for $74.76 \%$ of the total numbers, as shown in Table 3. The second leading classification was E06B007 with 185, followed by E06B003 with 72 .

Table 2. Distribution of patents granted by country in the technology field

\begin{tabular}{llccc}
\hline Rank & \multicolumn{1}{c}{ Country } & $\begin{array}{c}\text { Number } \\
\text { of } \\
\text { patents }\end{array}$ & $\begin{array}{c}\text { Percent } \\
\text { of } \\
\text { patents }\end{array}$ & $\begin{array}{c}\text { Cumulative } \\
\text { percentage }\end{array}$ \\
\hline 1 & $\begin{array}{l}\text { United States of } \\
\text { America (USA) }\end{array}$ & 464 & $62.53 \%$ & $62.53 \%$ \\
\hline 2 & Taiwan (TW) & 78 & $10.51 \%$ & $73.05 \%$ \\
\hline 3 & Canada (CA) & 35 & $4.72 \%$ & $77.76 \%$ \\
\hline 4 & Germany (DE) & 27 & $3.64 \%$ & $81.40 \%$ \\
\hline 5 & Japan (JP) & 24 & $3.23 \%$ & $84.64 \%$ \\
\hline 6 & France (FR) & 20 & $2.70 \%$ & $87.33 \%$ \\
\hline 7 & Italy (IT) & 13 & $1.75 \%$ & $89.08 \%$ \\
\hline 8 & Netherlands (NL) & 7 & $0.94 \%$ & $90.03 \%$ \\
\hline 9 & Austria (AT) & 7 & $0.94 \%$ & $90.97 \%$ \\
\hline 10 & Israel (IL) & 7 & $0.94 \%$ & $91.91 \%$ \\
\hline
\end{tabular}

Thus, the top 5 technology fields cover $88.95 \%$ of the patents. The core technology fields related to shading devices have been identified in this study. The technological development of this field is primarily contained within classification E06B009.

\subsection{Patent citation analysis}

This study used the INID code and patent numbers to find the corresponding patent references and extracted the reference citations for further patent citation analysis. Pajek software (Batagelj, Mrvar 1998) was used to construct the patent citation network for shading devices. The patent citation network consists of 5318 nodes and 10851 links, the average degree of each patent is 4.08 , and the average density is 0.00038 . This study applied SNA indicators such as degree centrality, betweenness centrality, and closeness centrality to measure which patents are in the center of the network. It can be effective in identifying core patents. First, the top 10 patents with high degree centrality were identified (Table 4). Patent 6644375, entitled Cordless blind brake, had the highest degree centrality within the citation network. This invention is related to cordless blinds and shades comprising a head rail, a bottom rail and a spring motor coupled to the lift cord and is designed to raise or lower the window covering; it can easy raise and lower the slats without a pair of lift cords used in traditional shading devices. This patent is important because the invention is used in a wide variety of blinds or shades such as venetian blinds, cellular blinds, pleated shades, and wood blinds. Patent 7059378 and 6688369 ranked second and third, respectively, in the given citation network. Those inventions are related to methods and apparatuses used for producing cellular fabric shading devices with adjustable vanes designed to control light passing through the shade. Patent 6112797, entitled Apparatus for fabricating a light control window covering, is related to fabric window coverings with adjustable vanes designed for controlling the amount of light admitted through the shade. The features of the above patents were focused on insulating properties associated with cellular fabric

Table 3. Top 5 technology fields for the area of shading device

\begin{tabular}{|c|c|c|c|c|c|}
\hline Rank & IPC & Description & $\begin{array}{l}\text { Number } \\
\text { of patents }\end{array}$ & $\begin{array}{l}\text { Percent of } \\
\text { patents }\end{array}$ & $\begin{array}{l}\text { Cumulative } \\
\text { percentage }\end{array}$ \\
\hline 1 & E06B009 & $\begin{array}{l}\text { Screening or protective devices for openings, with or without } \\
\text { operating or securing mechanisms; Closures of similar construction }\end{array}$ & 1,691 & $74.76 \%$ & $74.76 \%$ \\
\hline 2 & E06B007 & $\begin{array}{l}\text { Special arrangements or measures in connection with doors or } \\
\text { windows }\end{array}$ & 185 & $8.18 \%$ & $82.94 \%$ \\
\hline 3 & E06B003 & $\begin{array}{l}\text { Window sashes, door leaves, or like elements for closing openings; } \\
\text { Layout of fixed or moving closures, e.g. windows; Features of } \\
\text { rigidly-mounted outer frames relating to the mounting of wing } \\
\text { frames }\end{array}$ & 72 & $3.18 \%$ & $86.12 \%$ \\
\hline 4 & A $47 \mathrm{H} 005$ & Devices for drawing draperies, curtains, or the like & 47 & $2.08 \%$ & $88.20 \%$ \\
\hline 5 & A47H023 & Curtains; Draperies & 17 & $0.75 \%$ & $88.95 \%$ \\
\hline
\end{tabular}


Table 4. Degree centrality of the top 10 patents in the technology field

\begin{tabular}{|c|c|c|}
\hline $\begin{array}{l}\text { Patent } \\
\text { No. }\end{array}$ & Degree & Patent name \\
\hline 6644375 & 145 & Cordless blind brake \\
\hline 7059378 & 119 & Fabric light control window covering \\
\hline 6688369 & 118 & Fabric light control window covering \\
\hline 6112797 & 110 & $\begin{array}{l}\text { Apparatus for fabricating a light } \\
\text { control window covering }\end{array}$ \\
\hline 5793174 & 96 & $\begin{array}{l}\text { Electrically powered window } \\
\text { covering assembly }\end{array}$ \\
\hline 6474394 & 90 & Cordless, balanced window covering \\
\hline 6289965 & 86 & $\begin{array}{l}\text { Take-up drum for a cordless shade } \\
\text { counterbalance }\end{array}$ \\
\hline 6079471 & 85 & Cordless, balanced window covering \\
\hline 6571853 & 85 & $\begin{array}{l}\text { Cordless blind having variable } \\
\text { resistance to movement }\end{array}$ \\
\hline 6234236 & 84 & Cordless balanced window covering \\
\hline
\end{tabular}

shades of window coverings, which were characterized as flexible material and have a softer appearance than traditional shading devices. Unlike the above patents, Patent 5793174, entitled Electrically powered window covering assembly, is related to apparatuses and methods used for assembling electrically adjustable shading devices, which are activated by a wireless remote control signal generated and sent by a transmitter. Likewise, the inventions connected to the other five patents are also related to cordless blinds or window shades, which eliminate the conventional pull cords and cordlock mechanisms; this new device moves the slats from a horizontal to a vertical position in order to open and close the blinds or shades with respect to the passage of light. Table 4 clearly shows that patent 6644375 had the highest degree centrality in the given citation network, which means it had the highest number of citations among patents in this field. It has distinguished the relationship between patents with a high number of citations in the citation network, and those less cited. The result showed that patents with higher degree centrality were often cited by many other patents and that their position was in the center of the network. Degree centrality analysis can help to find patents with large numbers of citations and point out important patents having strong influence in promoting technology innovation in this field.

Second, the top 10 patents with high betweenness centrality were identified (Table 5). Patent 5320154 had the highest betweenness centrality in the citation network. This invention is related to apparatuses and methods of roller shades having several transverse vanes connecting two parallel slats for covering various architectural openings; it provides a means for rolling and unrolling a layered light control-covering device. Patent 6289964 is related to a control system with a ro-
Table 5. Betweenness centrality of the top 10 patents in the technology field

\begin{tabular}{|c|c|c|}
\hline Patent No. & Betweenness & Patent name \\
\hline 5320154 & 0.00015 & $\begin{array}{l}\text { Method and apparatus for } \\
\text { mounting a retractable window } \\
\text { covering }\end{array}$ \\
\hline 6289964 & 0.00013 & $\begin{array}{l}\text { Control and suspension system } \\
\text { for a covering for architectural } \\
\text { openings }\end{array}$ \\
\hline 5133399 & 0.00012 & $\begin{array}{l}\text { Apparatus by which horizontal } \\
\text { and vertical blinds, pleated } \\
\text { shades, drapes and the like } \\
\text { may be balanced for "no load" } \\
\text { operation }\end{array}$ \\
\hline 5117893 & 0.00011 & Rolling shutter system \\
\hline 4807686 & 0.00011 & Shade system \\
\hline 5692550 & 0.00010 & Cellular shade material \\
\hline 4644990 & 0.00009 & $\begin{array}{l}\text { Automatic closing system for } \\
\text { window blinds }\end{array}$ \\
\hline 5887386 & 0.00008 & $\begin{array}{l}\text { Window shutters with movable } \\
\text { louvers }\end{array}$ \\
\hline 5141041 & 0.00008 & $\begin{array}{l}\text { Stepped multi-cellular window } \\
\text { shade }\end{array}$ \\
\hline 5706876 & 0.00007 & $\begin{array}{l}\text { Cordless, roller bar cellular } \\
\text { shade }\end{array}$ \\
\hline
\end{tabular}

tating element for suspending and controlling the operation of a panel to cover an architectural opening. Patent 5133399 is related to horizontal and vertical blinds or pleated shades without a pull cord for raising and lowering the blinds or shades. Patent 5117893 is related to a rolling shutter system comprised of a rolling shutter and a bi-directional drive for raising and lowering the rolling shutter; it can easily be installed, features quick manual operation and improves a building's appearance relative to traditional patents. Patent 4807686 is related to a motorized window shade system that is adaptable to both automatic and manual operation and contains electrical circuitry for recharging a battery power source within the system. Patent 5692550, 5141041 , and 5706876 are related to cellular pleated shades with retracting mechanisms that can expand and retract the shades to provide insulation. In particular, patent 4644990 is related to methods and apparatuses designed for automatically closing window shades in response to an increasing level of solar energy through the window. Patent 5887386 is related to methods and apparatuses designed to produce window shutters with movable louvers, a compression spring system and a tensioning mechanism designed to raise and lower the shutters. The result showed that these patents with higher betweenness centrality in a network fulfil a crucial role and significantly aid information spread and knowledge diffusion.

Third, the top 10 patents with high closeness centrality were identified (Table 6), of which seven are strongly 
related to cordless window coverings and three to fabric light control window coverings. In this study, the patent of degree analysis and closeness analysis were almost identical except for patents 5793174 and 5706876; the technologies of these closely related patents have been described in the previous degree analysis and were similar to each other and homogeneous. This paper found that the top nine patents with high closeness centrality also have high degree centrality, indicating that the technolo-

Table 6. Closeness centrality of the top 10 patents in the technology field

\begin{tabular}{lcl}
\hline $\begin{array}{l}\text { Patent } \\
\text { No. }\end{array}$ & Closeness & \multicolumn{1}{c}{ Patent name } \\
\hline 6644375 & 0.23938 & Cordless blind brake \\
\hline 6079471 & 0.23298 & $\begin{array}{l}\text { Cordless, balanced window } \\
\text { covering }\end{array}$ \\
\hline 6474394 & 0.23270 & $\begin{array}{l}\text { Cordless, balanced window } \\
\text { covering }\end{array}$ \\
\hline 7059378 & 0.23047 & $\begin{array}{l}\text { Fabric light control window } \\
\text { covering }\end{array}$ \\
\hline 6112797 & 0.23044 & $\begin{array}{l}\text { Apparatus for fabricating a light } \\
\text { control window covering }\end{array}$ \\
\hline 6289965 & 0.23014 & $\begin{array}{l}\text { Take-up drum for a cordless } \\
\text { shade counterbalance }\end{array}$ \\
\hline 6688369 & 0.22976 & $\begin{array}{l}\text { Fabric light control window } \\
\text { covering }\end{array}$ \\
\hline 6571853 & 0.22936 & $\begin{array}{l}\text { Cordless blind having variable } \\
\text { resistance to movement }\end{array}$ \\
\hline 6234236 & 0.22904 & $\begin{array}{l}\text { Cordless balanced window } \\
\text { covering }\end{array}$ \\
\hline 5706876 & 0.22602 & \begin{tabular}{l} 
Cordless, roller bar cellular shade \\
\hline
\end{tabular} \\
\hline
\end{tabular}

gies of these patents were important and closely related to each other through citation. In particular, patent 6644375 had the highest degree centrality and closeness centrality. The last patent with higher closeness centrality was also ranked last in the betweenness analysis, indicating that patent had shorter distances and more quickly spreading knowledge to other patents within the citation network. The result showed that patents with higher closeness centrality also had a higher degree centrality in a network, which diffuses knowledge quickly with others in its field.

In the patent citation network, each node represents a patent and each link represents a citation relationship. In order to present the citation relationships between patents more clearly, this paper used patents with minimum degree centrality by gradually increasing degree centrality of patents to reduce the citation network and provide visibility. It reduced the size of the citation network and transformed the original network to create a new network. After removing patents with a degree lower than six from the citation network, only patents with a degree equal to or higher than six would be shown within the new network. This process was used to produce a well-displayed citation network (Fig. 5); in this graph, connecting lines are directed from cited patents to citing patents to represent the diffusion of knowledge and technology.

\subsection{Patent citation analysis by assignees}

Furthermore, this study collected data from the forward citations of patent assignees to understand linkages between potential competitors. Then, this study applied the social network method to explore the technological

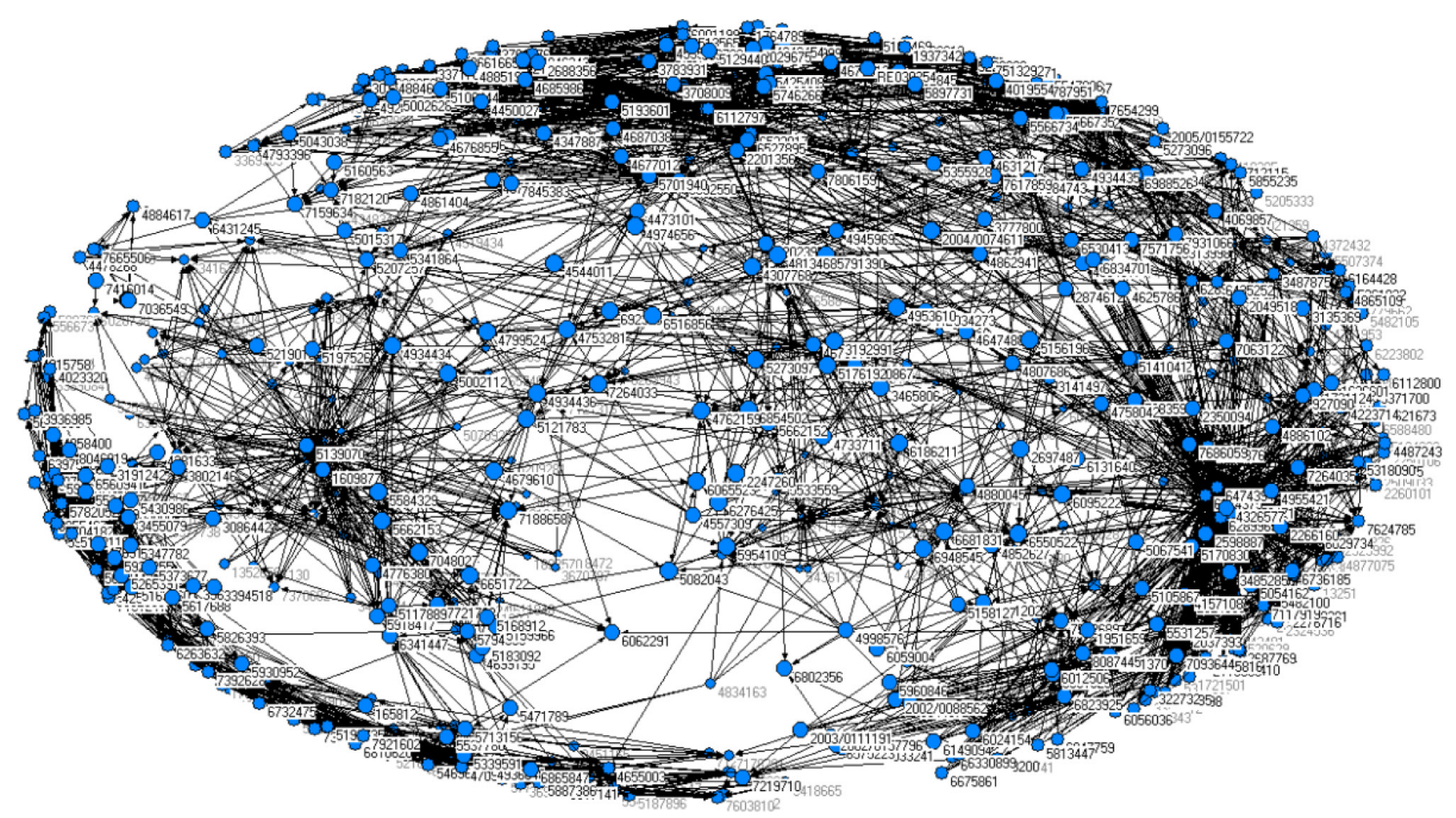

Fig. 5. Reduction of citation network of patents in the technology field 
correlations of patent assignees and discovered the linkages between patent assignees, as shown in Figure 6. In the patent assignee network, every node is an assignee and a line shows the relationships between assignees. It provided an overview of the assignee network based on patent citation data. The assignees network of this study consists of 254 nodes and 1404 links (Fig. 6), the average degree of each patent is 23.3 , and the average density is 0.09209 . The average density in the assignees network was higher than that in the citation network, which implied that it was a higher connected network. This study then applied SNA indicators to identify active assignees. As shown in Table 7, the study presented the top 10 patent assignees with higher degree centrality, betweenness centrality, and closeness centrality in the assignees network.

Table 7 clearly shows that Hunter Douglas Inc. had the highest degree centrality, which means Hunter Douglas Inc. was more active, influential, and important than other patent assignees within the technology domain; in this respect, Hunter Douglas Inc. was followed by Newell Window Furnishings, Inc. and Tapco International Corporation. The result of degree analysis in this study implied that the top 9 patent assignees had more than 100 relations in the assignee network, and played an important role in the knowledge diffusion process.

The result of betweenness analysis in this study also indicated that Hunter Douglas Inc. had the highest score, which means it played an important bridging role for passing information between competitors within the technology domain. In addition, Hunter Douglas Inc. also had the highest closeness centrality, indicating that had a closer relationship to other competitors, and was able to spread information through the network by shorter routes. The result implied that these close competitors' technologies were similar with each other.

This paper found that Hunter Douglas Inc. had the highest degree centrality, betweenness centrality, and closeness centrality within the network and played an important role in patent activity in the area of shading devices. It also indicated that Hunter Douglas Inc. was the most heavily influential competitor and the main knowledge diffusion center in the technology field.

\section{Main path analysis}

The main path analysis algorithm for citation network analysis is one of the SNA applications used to identify main technology development paths and knowledge diffusion. Hummon and Doreian (1989) proposed the concept of main path analysis to examine the links within the citation network, to find the main stream of research literature through the network. Batagelj (2003) proposed an efficient algorithm, called the search path count (SPC) method, for identifying the most important path of a citation network. This paper used Pajek software and main path analysis to generate and extract the main patent path from the original (unreduced) citation network, as shown in Figure 7. The main patent path represents the direction of knowledge flow and technology trajectory, and reflects the diffusion of knowledge and technology from prior arts. As shown in Table 8, the major patent distribution is understood, contributing to the comprehension of the primary patent technology.

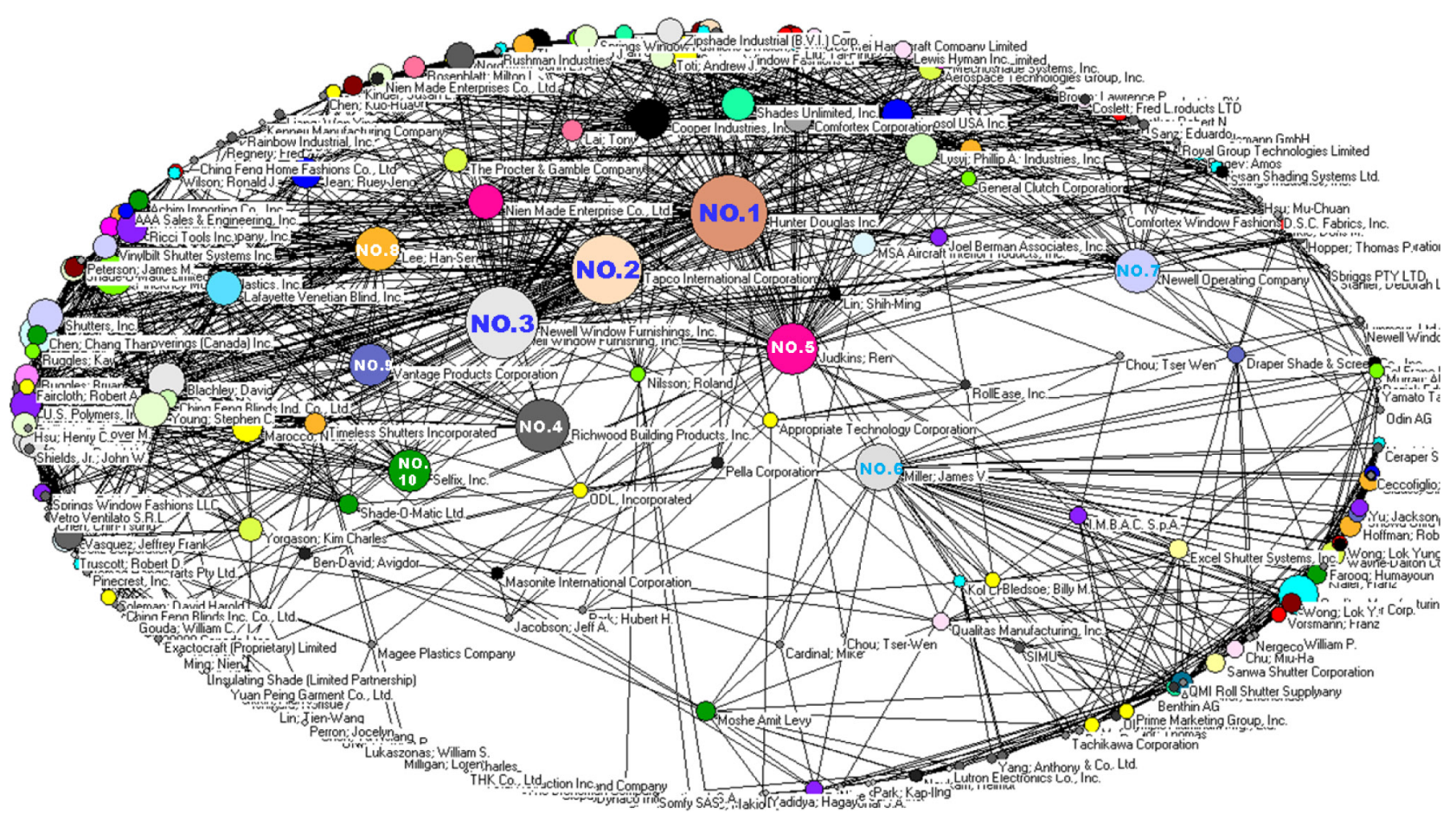

Fig. 6. The linkages between patent assignees in the technology field (patent assignee network) 
Table 7. Degree centrality, betweenness centrality, and closeness centrality of the top 10 patents assignees in the technology field

\begin{tabular}{|c|c|c|c|c|c|c|}
\hline Rank & Patent assignees & Degree & Patent assignees & Betweenness & Patent assignees & Closeness \\
\hline 1 & Hunter Douglas Inc. & 318 & Hunter Douglas Inc. & 0.50083 & Hunter Douglas Inc. & 0.59619 \\
\hline 2 & $\begin{array}{l}\text { Newell Window } \\
\text { Furnishings, Inc. }\end{array}$ & 281 & Miller; James V. & 0.22056 & Judkins; Ren & 0.46801 \\
\hline 3 & $\begin{array}{l}\text { Tapco International } \\
\text { Corporation }\end{array}$ & 277 & $\begin{array}{l}\text { Newell Window } \\
\text { Furnishings, Inc. }\end{array}$ & 0.09003 & $\begin{array}{l}\text { Newell Window } \\
\text { Furnishings, Inc. }\end{array}$ & 0.46435 \\
\hline 4 & $\begin{array}{l}\text { Richwood Building } \\
\text { Products, Inc. }\end{array}$ & 166 & Judkins; Ren & 0.08718 & $\begin{array}{l}\text { Nien Made Enterprise } \\
\text { Co., Ltd. }\end{array}$ & 0.45544 \\
\hline 5 & Judkins; Ren & 148 & $\begin{array}{l}\text { Nien Made Enterprise } \\
\text { Co., Ltd. }\end{array}$ & 0.04618 & Miller; James V. & 0.45544 \\
\hline 6 & Miller; James V. & 122 & $\begin{array}{l}\text { Newell Operating } \\
\text { Company }\end{array}$ & 0.03919 & $\begin{array}{l}\text { Lafayette Venetian } \\
\text { Blind, Inc. }\end{array}$ & 0.45025 \\
\hline 7 & $\begin{array}{l}\text { Newell Operating } \\
\text { Company }\end{array}$ & 115 & $\begin{array}{l}\text { Tapco International } \\
\text { Corporation } \\
\end{array}$ & 0.03260 & Cooper Industries, Inc. & 0.44855 \\
\hline 8 & Lee; Han-Sen & 107 & Cooper Industries, Inc. & 0.02987 & $\begin{array}{l}\text { Newell Operating } \\
\text { Company }\end{array}$ & 0.43941 \\
\hline 9 & Selfix, Inc. & 101 & Kol Chen Ltd. & 0.02624 & $\begin{array}{l}\text { Tapco International } \\
\text { Corporation }\end{array}$ & 0.43941 \\
\hline 10 & $\begin{array}{l}\text { Vantage Products } \\
\text { Corporation }\end{array}$ & 99 & $\begin{array}{l}\text { Lafayette Venetian } \\
\text { Blind, Inc. }\end{array}$ & 0.02373 & Verosol USA Inc. & 0.43459 \\
\hline
\end{tabular}

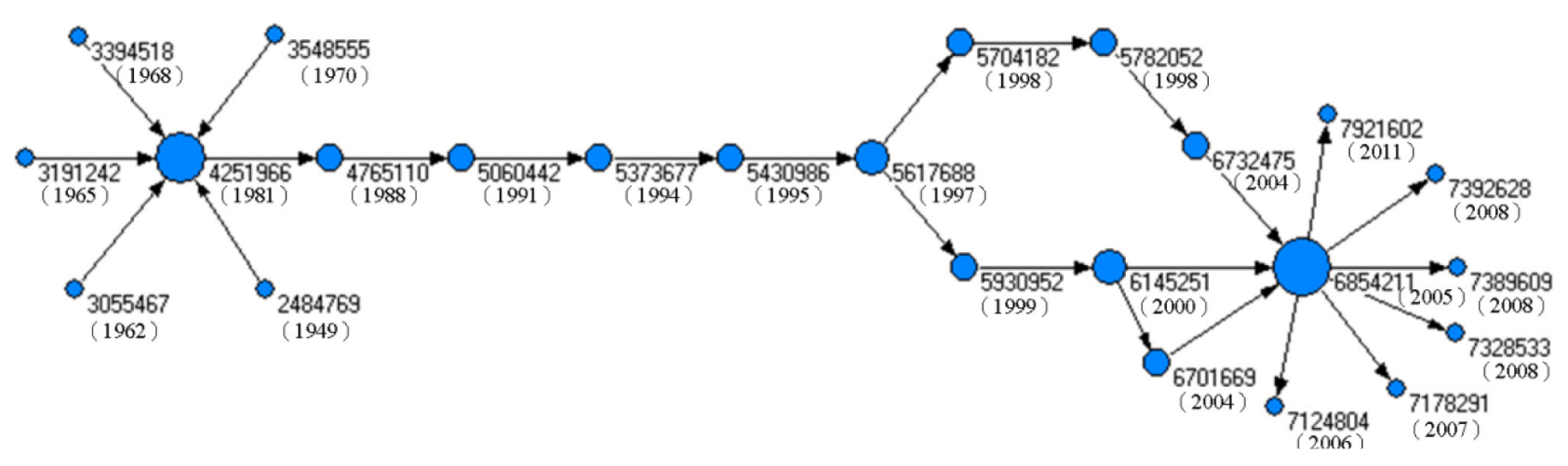

Fig. 7. Main path for 24 most often cited patents in the technology field

According to the result of main path analysis, this study has discussed and described the changes in the technological development of shading devices. This study divided the changes of the technological development of shading devices into three separate phases (Table 9). During the first phase, from 1949 to 1980 , the features of patents focused on framed or fixed shading devices made of wood, plastic or metal materials, which included louvered windows or louvered shutter with rigid plates, apparatuses and methods of making the same shutter construction, metal panel structure of shutters, and shutter structure. During the second phase, from 1981 to 2000, shading devices for architectural openings became mobile, with adjustable types of shutters designed to achieve shading, and were produced in units for rapid assembly. The features of the patents focused on adjustable shutters made of thin plastic or metal materials, shutters with movable plates, panels or slats, adjustable length louvers, apparatuses and methods of assembling shutters, which were cheaper, lighter, and allowed more rapid assembly and installation relative to previous designs. The problem with manually adjustable shading devices was that they require manual operation to change the degree of shading; this type of design is not able to immediately adapt to the changes in sunlight, making them inconvenient and inefficient to use. During the third phase, from 2001 to 2011, shading devices became multifunctional, using electric motors and automatic controls. The features of the patents focused on shutters with a rotation mechanism or a tilt control, customizable shutters, methods of assembling shutters, an automated shutter control device comprising slats, a connector portion, and a motor charged by solar energy to open and close the slats, and apparatuses and methods involving louver rotation. In fact, one type of electric shading device required an external power source to control the angle of the slats for shading, resulting in poor economic utility. In response to this weakness, 
Table 8. Main path for 24 most often cited patents in the technology field

\begin{tabular}{|c|c|c|c|c|}
\hline Rank & Patent No. & Filed date & Issue date & Patent name \\
\hline 1 & 2484769 & $1945 / 07 / 25$ & $1949 / 10 / 11$ & Plastic window ventilator \\
\hline 2 & 3055467 & $1960 / 02 / 15$ & $1962 / 09 / 25$ & Shutter construction and method of making the same \\
\hline 3 & 3191242 & $1961 / 01 / 03$ & $1965 / 06 / 29$ & Simulated louvered shutter \\
\hline 4 & 3394518 & $1966 / 11 / 22$ & $1968 / 07 / 30$ & Metallic panel structure \\
\hline 5 & 3548555 & $1969 / 01 / 10$ & $1970 / 12 / 22$ & Shutter structure \\
\hline 6 & 4251966 & $1979 / 03 / 13$ & $1981 / 02 / 24$ & Adjustable height shutter \\
\hline 7 & 4765110 & $1982 / 09 / 23$ & $1988 / 08 / 23$ & Adjustable plastic shutter \\
\hline 8 & 5060442 & $1990 / 10 / 16$ & $1991 / 10 / 29$ & Louvered plastic building product \\
\hline 9 & 5373677 & $1994 / 06 / 17$ & $1994 / 12 / 20$ & Shutter assembly with grooved edge \\
\hline 10 & 5430986 & $1993 / 12 / 27$ & $1995 / 07 / 11$ & Shutter assembly \\
\hline 11 & 5617688 & $1996 / 04 / 16$ & $1997 / 04 / 08$ & Adjustable shutter with reversible end cap \\
\hline 12 & 5704182 & $1995 / 06 / 06$ & $1998 / 01 / 06$ & Modular shutter assembly \\
\hline 13 & 5782052 & $1997 / 05 / 19$ & $1998 / 07 / 21$ & Omamental shutter \\
\hline 14 & 5930952 & $1997 / 11 / 28$ & $1999 / 08 / 03$ & Shutter frame member with adjustable component parts \\
\hline 15 & 6145251 & $1999 / 09 / 17$ & $2000 / 11 / 14$ & $\begin{array}{l}\text { Adjustable shutter assembly and slat control mechanism using a } \\
\text { control gear and gear engaging positioner }\end{array}$ \\
\hline 16 & 6701669 & $2002 / 09 / 10$ & $2004 / 03 / 09$ & Shutter system rotation mechanism \\
\hline 17 & 6732475 & $2000 / 04 / 03$ & $2004 / 05 / 11$ & User customizable shutter system \\
\hline 18 & 6854211 & $2003 / 01 / 28$ & $2005 / 02 / 15$ & Removable louver and tilt control \\
\hline 19 & 7124804 & $2004 / 05 / 12$ & $2006 / 10 / 24$ & Blind slat assembly for door/window venetian blind \\
\hline 20 & 7178291 & $2004 / 02 / 25$ & $2007 / 02 / 20$ & Automated shutter control \\
\hline 21 & 7328533 & $2004 / 07 / 26$ & $2008 / 02 / 12$ & Window shutter opening and closing device \\
\hline 22 & 7389609 & $2004 / 03 / 12$ & $2008 / 06 / 24$ & Louver rotation apparatus and method \\
\hline 23 & 7392628 & $2006 / 01 / 05$ & $2008 / 07 / 01$ & Functional shutter \\
\hline 24 & 7921602 & $2005 / 12 / 15$ & $2011 / 04 / 12$ & Shutter assembly \\
\hline
\end{tabular}

Table 9. Technology development of shading devices

\begin{tabular}{lcl}
\hline Phase & Year & \multicolumn{1}{c}{$\begin{array}{c}\text { Characteristics of } \\
\text { technologies }\end{array}$} \\
\hline First phase & $1949 \sim 1980$ & $\begin{array}{l}\text { Wood, plastic, metal, framed, } \\
\text { fixed }\end{array}$ \\
\hline $\begin{array}{l}\text { Second } \\
\text { phase }\end{array}$ & $1981 \sim 2000$ & $\begin{array}{l}\text { Mobile, adjustable, produced } \\
\text { in units, fast assembly }\end{array}$ \\
\hline Third phase & 2001 2011 & $\begin{array}{l}\text { Multifunctional, electric } \\
\text { motors, automatic control }\end{array}$ \\
\hline
\end{tabular}

shading devices using automatic sensor controls were developed, revealing gaps where technological improvement is required. From the viewpoint of technology innovation and energy saving, this study suggests that automatic sensing shading devices that control the angle of the slats for the optimal shading effect might be the focus of technological development. To optimally reduce energy consumption, such a device should effectively respond to the environment and to climate change and prevent sunlight from entering indoors.

\section{Conclusions}

This study searched the database of the USPTO for granted patents related to our research subject, then con- ducted a quantitative statistical analysis using the patents' bibliographic information and portrayed a visual patent citation network based on the social network method to analyze the overall process of patent citation and the technological correlations of patent assignees. The purpose of this study was to explore the current status of patent activity, major assignees, assignee countries, core technology fields, patent citations, potential competitors, and developmental path.

The results of the patent analysis indicated that the number of applied patents significantly declined after 2004, and that industries and agents working in the area of shading devices must renew their efforts to develop innovative future technology. The majority of the patent assignees were companies and corporations, and Hunter Douglas Inc. was the leading assignee, as they hold the highest number of granted patents. It also indicated that Hunter Douglas Inc. was the most heavily influential competitor and the main knowledge diffusion center in the technology field. According to the IPC analysis, the technology focused on E06B009 followed by E06B007. In the country analysis of assignees, the USA held the greatest number of granted patents in the technology field, and Taiwan was ranked 
second. The patents that were ranked high by SNA indicators reduced the use of conventional pull cords and increased the use of flexible materials, had a softer appearance, as well as employed cordless blinds, vertically adjustable shades, motorized shades with spring motors, electrically and automatic shading devices; this confirms both the technological importance of the patents and their characteristics. The result of main path analysis found that automatic shading device, which was similar to the specific invention of patents with high degree centrality and betweenness centrality in SNA, was considered to be at the forefront of technological trend. Specifically, the main path analysis identified overall and specific technological trend, which can help experts to develop strategies and make decisions related to technological development. From the viewpoint of technological innovation and energy saving, this study suggests that automatic sensing shading devices have become the focus of technological development. The analysis results of this study provide evidence for, and a clear picture of, the pattern of shading device technology over the past 38 years.

The limits of a patent analysis in this study include practical operational concerns, time gaps, and relationships based on the territorial principle. Therefore, information used for patent analysis is limited to that taken from databases in a searched country; different countries require individual searches and analyses. Future research should explore the non-patent literature including journals, articles, and conference papers, in the field of shading devices based on SNA and the TRIZ method of innovation design.

\section{Acknowledgements}

The authors would like to acknowledge the National Science Council of the Republic of Taiwan (R.O.C.) for financially supporting this research under Contract No. NSC98-2221-E011-125. We would like to thank the editors and anonymous reviewers for their valuable comments and suggestions, which have significantly improved this paper. We also thank Dr John S. Liu, and C. H. Kuan, for their helpful discussions of the paper.

\section{References}

Albert, M. B.; Avery, D.; Narin, F.; Mcallister, P. 1991. Direct validation of citation counts as indicators of industrially important patents, Research Policy 20: 251-259. http://dx.doi.org/10.1016/0048-7333(91)90055-U

Batagelj, V. 2003. Efficient algorithms for citation network analysis. Computing Research Repository. cs.DL/0309.

Batagelj, V.; Mrvar, A. 1998. Pajek - Program for large network analysis, Connections 21: 47-57.

Boyd, D. M.; Ellison, N. B. 2007. Social network sites: definition, history, and scholarship, Journal of Computer-Mediated Communication 13: 210-230. http://dx.doi.org/10.1111/j.1083-6101.2007.00393.x

Carpenter, M. P.; Narin, F.; Woolf, P. 1981. Citation rates to technologically important patents, World Patent Information 3: 160-163. http://dx.doi.org/10.1016/0172-2190
Chang, S.-B.; Lai, K.-K.; Chang, S.-M. 2009. Exploring technology diffusion and classification of business methods: using the patent citation network, Technological Forecasting and Social Change 76: 107-117. http://dx.doi.org/10.1016/j.techfore.2008.03.014

Chen, Y.-S.; Chen, B.-Y. 2011. Utilizing patent analysis to explore the cooperative competition relationship of the two LED companies: Nichia and Osram, Technological Forecasting and Social Change 78: 294-302. http://dx.doi.org/10.1016/j.techfore.2010.06.017

Cheng, A.-C. 2012. Exploring the relationship between technology diffusion and new material diffusion: the example of advanced ceramic powders, Technovation 32: 163-167. http://dx.doi.org/10.1016/j.technovation.2011.10.008

Cho, S.-H.; Shin, K.-S.; Zaheer-Uddin, M. 1995. The effect of slat angle of windows with venetian blinds on heating and cooling loads of buildings in South Korea, Energy 20: 12251236. http://dx.doi.org/10.1016/0360-5442(95)00074-Q

Co, C. 2002. Evolution of the geography of innovation: evidence from patent data, Growth and Change 33: 393-423. http://dx.doi.org/10.1111/1468-2257.00204

Daim, T. U.; Intarode, N. 2009. A framework for technology assessment: case of a Thai building material manufacturer, Energy for Sustainable Development 13: 280-286. http://dx.doi.org/10.1016/j.esd.2009.10.006

Datta, G. 2001. Effect of fixed horizontal louver shading devices on thermal perfomance of building by TRNSYS simulation, Renewable Energy 23: 497-507. http://dx.doi.org/10.1016/S0960-1481(00)00131-2

Ernst, H. 1995. Patenting strategies in the German mechanical engineering industry and their relationship to company performance, Technovation 15: 225-240. http://dx.doi.org/10.1016/0166-4972(95)96605-S

Ernst, H. 1997. The use of patent data for technological forecasting: the diffusion of CNC-Technology in the machine tool industry, Small Business Economics 9: 361-381. http://dx.doi.org/10.1023/A:1007921808138

Florides, G. A.; Kalogirou, S. A.; Tassou, S. A.; Wrobel, L. C. 2000. Modeling of the modern houses of Cyprus and energy consumption analysis, Energy 25: 915-937. http://dx.doi.org/10.1016/S0360-5442(00)00030-X

Freeman, L. C. 1978. Centrality in social networks conceptual clarification, Social Networks 1: 215-239. http://dx.doi.org/10.1016/0378-8733(78)90021-7

Globerman, S.; Kokko, A.; Sjöholm, F. 2000. International technology diffusion: evidence from swedish patent data, Kyklos 53(1): 17-38. http:/dx.doi.org/10.1111/1467-6435.00107

Griliches, Z. 1990. Patent statistics as economic indicators: a survey, Journal of Economic Literature 28: 1661-1707.

Hanel, P. 2006. Intellectual property rights business management practices: a survey of the literature, Technovation 26: 895931. http://dx.doi.org/10.1016/j.technovation.2005.12.001

Hu, M.-C. 2008. Knowledge flows and innovation capability: the patenting trajectory of Taiwan's thin film transistor-liquid crystal display industry, Technological Forecasting and Social Change 75: 1423-1438. http://dx.doi.org/10.1016/j.techfore.2008.04.005

Hummon, N. P.; Dereian, P. 1989. Connectivity in a citation network: the development of DNA theory, Social Networks 11: 39-63. http://dx.doi.org/10.1016/0378-8733(89)90017-8

Karki, M. M. S. 1997. Patent citation analysis: a policy analysis tool, World Patent Information 19: 269-272. http://dx.doi.org/10.1016/S0172-2190(97)00033-1

La Rocca, G.; Tooren, M. V. 2012. Knowledge based engineering to support complex product design, Advanced Engineering Informatics 26: 157-158. http://dx.doi.org/10.1016/j.aei.2012.02.008 
List, J. 2010. An A to X of patent citations for searching, World Patent Information 32: 306-312. http://dx.doi.org/10.1016/j.wpi.2010.01.004

Ma, Z.; Lee, Y. 2008. Patent application and technological collaboration in inventive activities: 1980-2005, Technovation 28: 379-390. http://dx.doi.org/10.1016/j.technovation.2007.07.011

Mcaleer, M.; Slottje, D. 2005. A new measure of innovation: the patent success ratio, Scientometrics 63: 421-429. http://dx.doi.org/10.1007/s11192-005-0222-2

Michel, J.; Bettels, B. 2001. Patent citation analysis. A closer look at the basic input data from patent search reports, Scientometrics 51: 185-201. http://dx.doi.org/10.1023/A:1010577030871

Palmero-Marrero, A. I.; Oliveira, A. C. 2010. Effect of louver shading devices on building energy requirements, Applied Energy 87: 2040-2049. http://dx.doi.org/10.1016/j.apenergy.2009.11.020

Patel, D.; Ward, M. R. 2011. Using patent citation patterns to infer innovation market competition, Research Policy 40: 886-894. http://dx.doi.org/10.1016/j.respol.2011.03.006

Schmoch, U. 1993. Tracing the knowledge transfer from science to technology as reflected in patent indicators, Scientometrics 26: 193-211. http://dx.doi.org/10.1007/BF02016800

Scott, J. 1988. Social Network Analysis, Sociology 22: 109127. http://dx.doi.org/10.1177/0038038588022001007

Sorenson, O.; Rivkin, J. W.; Fleming, L. 2006. Complexity, networks and knowledge flow, Research Policy 35: 994-1017. http://dx.doi.org/10.1016/j.respol.2006.05.002
Spear, B. 1996. Patent information on the internet, World Patent Information 18: 33-37. http://dx.doi.org/10.1016/0172-2190(95)00057-7

Trappey, C. V.; Wu, H.-Y.; Taghaboni-Dutta, F.; Trappey, A. J. C. 2011. Using patent data for technology forecasting: China RFID patent analysis, Advanced Engineering Informatics 25: 53-64. http://dx.doi.org/10.1016/j.aei.2010.05.007

Wilson, R. M. 1987. Patent analysis using online databases - II. Competitor activity monitoring, World Patent Information 9: 73-78. http://dx.doi.org/10.1016/0172-2190

Wu, C.-Y.; Mathews, J. A. 2012. Knowledge flows in the solar photovoltaic industry: insights from patenting by Taiwan, Korea, and China, Research Policy 41: 524-540. http://dx.doi.org/10.1016/j.respol.2011.10.007

Yener, A. K. 1998. A method of obtaining visual comfort using fixed shading devices in rooms, Building and Environment 34: 285-291. http://dx.doi.org/10.1016/S0360-1323(98)00024-9

Yoon, J.; Choi, S.; Kim, K. 2011. Invention property-function network analysis of patents: a case of silicon-based thin film solar cells, Scientometrics 86: 687-703. http://dx.doi.org/10.1007/s11192-010-0303-8

Yoon, J.; Kim, K. 2011. Identifying rapidly evolving technological trends for R\&D planning using SAO-based semantic patent networks, Scientometrics 88: 213-228. http://dx.doi.org/10.1007/s11192-011-0383-0

Yuan, J.; Yue, W.; Su, C.; Wu, Z.; Ma, Z.; Pan, Y.; Ma, N.; Hu, Z.; Shi, F.; Yu, Z.; Wu, Y. 2010. Patent activity on water pollution and treatment in China - a scientometric perspective, Scientometrics 83: 639-651. http://dx.doi.org/10.1007/s11192-009-0126-7

Yeng-Horng PERNG. He is currently a Professor in the Department of Architecture at National Taiwan University of Science and Technology, Taipei, Taiwan. His research interests include data mining, decision support systems, risk management, project management, quality management, and game theory.

Yu-Ying HUANG. She is currently a PhD candidate in the Department of Architecture at National Taiwan University of Science and Technology, Taipei, Taiwan. She received her MSc degree in Graduate Institute of Technology Management from National Taiwan University of Science and Technology, Taipei, Taiwan. Her research interests include patent search, patent analysis, and data mining. 